\title{
Nursing interventions in schizophrenia: the importance of therapeutic relationship
}

\begin{abstract}
Schizophrenia is a serious mental illness with specific characteristics that may constitute some obstacles for the therapeutic relationship. The difficulties in understanding the symptomatology both by the patient and by the nurse constitute one of the major hurdles. We outline the objective of this mini-review to address the challenges of the therapeutic relationship between the nurse and the person with schizophrenia. As a methodology, we reflect on the practices experienced as a mental health nurse, conducting a review of the specific literature based on theoretical assumptions. Authenticity, empathy, understanding of illness and the person, nonstigmatization and the ability to work as a team are essential characteristics that the nurse must have for the therapeutic relationship to be effective. It is crucial to work with insights into the disease, the importance of adherence and the reduction of selfstigma. Establishing a therapeutic relationship with the person with schizophrenia is therefore a constant challenge that must accompany the various stages of the disease in cooperation with the family and the community.
\end{abstract}

Keywords: schizophrenia, therapeutic relationship nursing care
Volume 3 Issue 6 - 2017

\author{
Lara Guedes de Pinho,' Anabela Pereira,' \\ Cláudia Chaves ${ }^{2}$ \\ 'Departamento de Educação e Psicologia, Universidade de \\ Aveiro, Portugal \\ ${ }^{2}$ Escola Superior de Saúde de Viseu, Portugal
}

Correspondence: Lara Manuela Guedes de Pinho, Departamento de Educação e Psicologia, Universidade de Aveiro, Portugal,Tel 00351916545031,Email larapinho@ua.pt

Received: May 18, 2017 | Published: September 19, 2017

\section{Introduction}

Schizophrenia is a serious mental illness characterized by psychotic symptoms such as delusions, hallucinations and disorganization of thought and behaviour. Negative symptoms such as social isolation, lack of initiative, or lack of will and pleasure in activities that were previously enjoyable are also frequent. This symptomatology causes serious damage to social and occupational functioning. A person suffering from schizophrenia has difficulty understanding the symptoms and perceiving what is happening in the world around them, since they live in an unreal world, parallel to the real world. It is also difficult for others who are unaware of the disease to understand, so these individuals tend to be stigmatized. Thus, there is a tendency to distrust others and the individual becomes more and more isolated, delaying the beginning of the treatment, which aggravates the clinical picture even more. Often the first contact with the health services occurs sometimes after the appearance of the first symptoms.

As the person does not perceive the symptoms of schizophrenia and cannot distinguish what is real from what is not, there is often a lack of insight into the pathology, making the therapy relationship a constant challenge. The purpose of this mini review is to address the challenges of the therapeutic relationship between the nurse and the person with schizophrenia. As a methodology, we reflect on the practices experienced as a mental health nurse, conducting a review of the specific literature based on theoretical assumptions.

\section{Nursing interventions in schizophrenia}

The nursing assessment of the person with schizophrenia is a complex process in most cases, requiring the collection of data from several sources, since in the acute phase of the disease the person is rarely able to give reliable information. It is necessary to appeal to the family and significant people, as well as to clinical records when they exist. Initially a mental examination should be performed, identifying the present symptomatology, such as delusions, hallucinations, disorganization and negative symptomatology. In order for an adequate evaluation to be performed, the nurse must know the characteristic behaviours of this disorder.

As a nursing diagnosis in the presence of delusions, the Nursing Interventions Classification (NIC) defines Delusion Control (6440), which is defined as the provision of a safe and therapeutic environment to the patient in acute state of confusion..$^{2}$ Thus, in the presence of delusions, the nurses must demonstrate to patients that they accept that the patient has this belief, although they do not share the belief. It is important not to discuss or deny belief so as not to risk compromising trust. Reasonable doubt must therefore be used as a therapeutic technique. For example, "I understand that you believe this to be true, but I do not think the same." One should also reinforce reality and talk about things and people that are real, avoiding ruminant thinking in false beliefs. The nurse should also be attentive during feeding and taking medication, since the delirium of poisoning may be present and the patient may believe that the food or medication is to poison him. Thus, it may be necessary to confirm whether the patient has taken the medication. ${ }^{1,2}$

As for the presence of hallucinations, the NIC defines the nursing diagnosis of Hallucination Control (6510) as the promotion of safety, comfort and the hallucinating patient's orientation towards reality. ${ }^{2}$ Auditory hallucinations are the most frequent, so the nurse must observe certain signs, such as taking a listening posture, unmotivated laughter, talking to oneself, and blocks in thinking, lack of attention and distraction. In the presence of these signs, the nurse should avoid touching the patient without warning, as the touch may be understood as a threat. Nurses must display an attitude of acceptance to help the patient share the content of the hallucination. This sharing is important to avoid unwanted reactions towards the self or others, if command hallucinations are present. The hallucination should not be reinforced, and the word "voices" should be used to refer to it, avoiding the word "they" which may indicate validation. It is also essential to make the patient realize that the nurse does not share the perception by saying, 
"I know the voices for you are real, but I do not hear any voices." It is important that the patient understands that the voices are unreal and are part of the disease, and distraction techniques can be used to direct the patient towards reality. Listening to music or watching television may be a good technique to distract the patient from the attention given to auditory hallucinations. ${ }^{1,2}$ These interventions are intended to establish a relationship of empathy and trust with the patient, causing the patient to begin to be critical towards the disease so that new intervention strategies can be implemented.

\section{Establishing a therapeutic relationship}

The therapeutic relationship is defined as being an interaction between two people, in this case, the nurse-patient, in which the collaboration between both contributes to a curative climate, promoting growth and/or prevention of the disease. ${ }^{1}$ There are several obstacles to the therapeutic relationship between the nurse and the patients with schizophrenia, since they are usually desperate, with difficulty expressing their symptoms and fearful of consequences and with confronting the need to change. ${ }^{3}$

Furthermore, often the first contact with the health services is against their will, because of lack of insight.

Caring for these patients requires that nurses have a great capacity for understanding and empathy and non-stigmatization of mental illness, so that an effective and efficient therapeutic relationship can be established. The nurse must be able to see that beyond the symptoms, there is a person in terrible mental suffering, despair, hopelessness and incomprehension, and may even entertain suicidal thoughts. Nurses must be able to understand that these people live in a frightening unreal world and has difficulty distinguishing reality from delusions and hallucinations, because everything seems real to them. For all of these reasons, it takes a great deal of hard work for nurses to understand the person with schizophrenia who is suffering from a mental pathology and that it is essential to learn to live with symptoms and adhere to therapy to prevent relapse.

In order to establish a therapeutic relationship between the nurse and the person with schizophrenia, we can use Peplau's theory of interpersonal relations developed in 1952. This theory puts forth the first approach to nurses' action centred on provide care in partnership with the patient rather than doing things to the patient. ${ }^{4}$ Peplau states that nursing is a therapeutic interpersonal process between two or more people and that this interaction becomes therapeutic only when the nurse is aware of her communication and takes responsibility for it. Rogers reinforces this idea, pointing out that in a therapeutic relationship, one who assumes the role of helping the other must have a high level of self-knowledge, be genuine, authentic and capable of empathy. ${ }^{5}$ Peplau's theory of interpersonal relations is based on four psychobiological experiences that compel patients to develop constructive responses to need, frustration, conflict, and anxiety, and identifies four phases in the nurse/patient relationship, which begins with orientation, identification, exploitation and resolution. ${ }^{6}$

The orientation phase is extremely complex in these patients and crucial to the beginning of the relationship. What is essential at this stage is to have the patient understand the difficulties they are facing and the need for cooperation. The identification stage comes after the patient's awareness of the problem and disease, where there are interdependent setting targets. In the exploitation phase, the patient is expected to explore all the possibilities and services offered. ${ }^{5}$ At this stage, the nurse must make all the possibilities available for recovery known and present the psychosocial rehabilitation programmes. In the resolution phase, individual patient requirements must be met for completion of the relationship. ${ }^{5}$ That is, in patients with schizophrenia this phase only occurs after the entire process of psychosocial rehabilitation, when the patient is able to live with the disease and to be autonomous in meeting their own needs.

Therefore, establishing a therapeutic relationship is not easy, requiring special attention on the part of the nurse. Active listening and empathy are especially important and should focus on the patient's experiences. Authenticity is necessary, allowing the person to distinguish between what is part of the disease and what is not part of it, i.e., what is real and what is not. It is crucial to help the patient find their personal resources and identify achievable goals in the medium and long term and the means to achieve them. ${ }^{3}$

The therapeutic alliance presents some obstacles, so the nurse's ability to deal with the following is essential. ${ }^{3}$

i. The patient does not see a need for help and blocks the nurse's attempts to establish contact.

ii. The family may be scared by the situation feeling unwell.

iii. The patient has difficulty expressing requests for help, even though the relationship is accepted.

iv. The patient may express difficulties but does not participate in the relationship.

v. The patient engages in the relationship, but refuses to accept some symptoms as part of the disease.

In these cases, the nurses must be clear about the limits of their actions, explaining to the patients that non-treatment or nonacceptance may lead to them being a danger to themselves or others. In addition, patients must be informed that the legislation of most democratic countries provides for involuntary hospitalization in a psychiatric unit for symptom control. This option should be used only as a last resort as it is a painful situation for the person and may further compromise the therapeutic relationship. Therefore, the nurse's role is to prevent this from occurring. ${ }^{3}$

The first step in recovering the patient, where the nurse plays a preponderant role, is to ensure adherence to therapy in order to reduce symptoms. This is a complex task given that most patients tend to abandon medication not only because of the difficulty in understanding their own need, but also because of the side effects. It is therefore essential to convey to the patient how important compliance with the therapeutic regime is.

\section{In addition to the therapeutic relationship}

The effectiveness of nursing interventions in schizophrenia depends not only on patient performance, but also on the involvement of the entire family and society. This is extremely important in the recovery process. For this, a multidisciplinary and networked effort is crucial. Thus, the nurse's capacity for teamwork is also one of the essential characteristics.

Once the therapeutic relationship has been established, besides controlling medication, it is important to implement psychoeducation for the patient and the family regarding schizophrenia, symptomatology and the importance of adherence to treatment. Psychoeducation is a psychotherapeutic intervention that goes beyond 
the simple transmission of knowledge. Besides the understanding of the mental illness, its aim is to provide the capacity to deal with it. Psychoeducational programmes should therefore inform about the disease and its evolution as well as enabling the use of effective coping strategies to adapt to the disease, to awaken the patient to the warning signs of a psychotic crisis, and to prevent relapse. A further aim is to prevent or reduce the family burden, avoiding the appearance of a pathology in the family. ${ }^{7}$ Psychoeducation, when associated with adherence and psychosocial rehabilitation, has proven effective in preventing relapses and hospitalization. ${ }^{8}$

To build a strong therapeutic relationship, in addition to focusing on psychoeducational interventions, increasing insight and adherence to therapy, it is also important to include guidance towards recovery and away from self-stigma. ${ }^{9}$ The patient should also be part of a psychosocial rehabilitation programme, in which nurses must play an active role within their competencies, continuing the therapeutic relationship, and in articulation with the multidisciplinary team. Taking into consideration that the therapeutic relationship in the psychosocial rehabilitation of the patient, family and community is more than a technical intervention, it is an ethical imperative.

\section{Conclusion}

In conclusion, we believe that establishing a therapeutic relationship with the person with schizophrenia is a constant challenge and must accompany the various stages of the disease in cooperation with the family and the community. Before committing to this relationship, the nurses must have a vast knowledge about themselves and the disease, knowing their limits and eliminating any existing stigma in relation to the patient. Following this growth and initial preparation, it is crucial to establish a commitment to the patient and to work the insight to the disease, the importance of adherence and reduction of self-stigma. For nursing care to produce effective results in the recovery process of these patients it is necessary to establish a solid and continuous therapeutic relationship with constant monitoring not only of the patient, but also of the surrounding environment involving the family and the community in the process. Establishing a therapeutic relationship in the light of Peplau's theory of interpersonal relations is an option that we consider practicable and that can bring satisfactory results, provided nurses know how to use it appropriately, following the four phases, taking into account the each patient's rhythm in the recovery process. We believe that establishing this relationship will produce positive results in nursing care.

\section{Acknowledgements}

None.

\section{Conflict of interest}

The author declares no conflicts of interest.

\section{References}

1. Townsend MC. Enfermagem em Saúde Mental e Psiquiátrica-conceitos de cuidado na prática baseada na evidência. Portugal: Lusociência; 2011.p. 507-534.

2. Bulechek GM, Butcher HK, Dochterman JM. NIC-Classificação das Intervenções de Enfermage. 5th ed. Rio de Janeiro, Brasil: Elsevier Editora; 2010. p. 130-267.

3. Favrod J, Maire A. Recuperar da Esquizofrenia. 1st ed. Portugal: Lusociência, Loures; 2014. p. 15-36.

4. Sitzman KL, Eichelberger LW. Understanding the work of nurse theorists- a creative beginning. 2nd ed. Sudbury, Massachusetts, USA: Jones and Bartlett Publishers; 2011. p. 147-151.

5. Peplau H. Relaciones interpersonales en enfermeria. Barcelona, Espanha: Salvat Editores; 1990. p. 11-36.

6. Rogers CR. A terapia centrada no paciente. Lisboa, Portugal: Moraes Editores; 1974.

7. Pfammatter M, Andres K, Brenner H. Manual de Psicoeducação e Gestão da Doença na esquizofrenia. Edição Encontrar-se; 2012.

8. Bonsack C, Rexhaj S, Favrod J. Psychoéducation: définition, historique, intérêt et limites. Annales Médico-psychologiques, Revue Psychiatrique. 2015;173(1):79-84.

9. Kvrgic S, Cavelti M, Beck EM, et al. Therapeutic alliance in schizophrenia: the role of recovery orientation, self-stigma, and insight. Psychiatry Res. 2013;209(1):15-20. 